\title{
ESTIMATION OF PROCESS CAPABILITY BASED ON CONTINUOUS AND ATTRIBUTE DATA
}

\author{
Biserka RUNJE, Živko KONDIĆ, Amalija HORVATIĆ NOVAK, Zdenka KERAN
}

\begin{abstract}
In the paper, a process capability and process performance analyses for continuous and attribute data are conducted by using an industry example. The inner diameter of the bearing rings is analysed by applying the normal capability analysis for the continuous data and by applying the binomial capability analysis for the attribute data. In order to quantify the process performance and process capability for continuous and attribute data, the sigma level or the process sigma is calculated. This represents an alternative method to calculating process capability indices and process performance indices.
\end{abstract}

Keywords: attribute data; continuous data; process capability; process performance; sigma level

\section{INTRODUCTION}

Process capability can be defined as the ability of the process to produce products/services which satisfy the requirements and needs determined by the customers themselves. Process capability studies can be conducted by using either the continuous or attribute data [1]. Continuous data is quantitative data and can contain an infinite number of values. Attribute data is data that has the quality or attribute characteristic that can be counted for recording and for the analysis.

Before process capability could be assessed, the process needed to be brought under control [2-4]. In the paper, the $p$ control chart and $X$ bar - $R$ control chart were used to bring and keep the process under statistical control. The capability of attribute data was estimated by using the binomial distribution while the capability of continuous data was estimated by using the normal distribution. In order to compare a variable process to an attribute process, a sigma level (Z-score and Z.Bench) was used [5-7].

\section{PROCES CAPABILITY ANALYSIS}

The paper tracks the daily production of rings $(N=100$ pcs) for a period of 25 days. The control of the production process was carried out through the application of the "100\% control" process on the inner diameter of the bearing rings $(\mathrm{LSL}=62.943 \mathrm{~mm} \leq$ inner diameter $\leq \mathrm{USL}=63.050 \mathrm{~mm})$. The diameter of the ring was controlled through the use of the "go - no go" method and the number of non-conforming units was ascertained (Tab. 1). The results of the nonconforming units under the lower specification limits (LSL) and above the upper specification limits (USL) are presented in Tab. 1.

Table 1 Number of non-conforming units

\begin{tabular}{|l|l|l|l|l|l|l|l|l|l|l|l|l|l|}
\hline & \multicolumn{10}{|c|}{ Number of non-conforming units } \\
\hline LSL & 2 & 0 & 0 & 0 & 0 & 0 & 0 & 0 & 0 & 0 & 1 & 0 & 0 \\
\hline USL & 0 & 1 & 2 & 0 & 2 & 0 & 1 & 2 & 1 & 0 & 1 & 2 & 0 \\
\hline & \multicolumn{10}{|c|}{ Number of non-conforming nits } \\
\hline LSL & 0 & 0 & 0 & 0 & 0 & 1 & 0 & 0 & 0 & 1 & 0 & 0 & \\
\hline USL & 1 & 1 & 0 & 0 & 0 & 1 & 2 & 0 & 1 & 0 & 1 & 1 & \\
\hline
\end{tabular}

Considering the attributive nature of the data, the $p$ control chart was used to ascertain whether the process was

Table 2 Inner diameter in $\mathrm{mm}$

\begin{tabular}{|c|c|c|c|c|}
\hline \multicolumn{5}{|c|}{ Sample No. } \\
\hline 1. & 2. & 3. & 4. & 5. \\
\hline 62.986 & 62.997 & 62.980 & 62.967 & 63.017 \\
\hline 62.963 & 63.024 & 63.012 & 62.989 & 62.992 \\
\hline 62.980 & 63.013 & 62.971 & 63.017 & 62.994 \\
\hline 62.996 & 63.010 & 62.974 & 62.989 & 63.010 \\
\hline 62.973 & 63.014 & 62.996 & 62.968 & 62.995 \\
\hline \multicolumn{5}{|c|}{ Sample No. } \\
\hline 6. & 7. & 8. & 9. & 10. \\
\hline 62.980 & 63.017 & 62.997 & 62.997 & 62.999 \\
\hline 63.018 & 62.975 & 62.981 & 62.985 & 62.983 \\
\hline 63.017 & 62.981 & 63.043 & 63.020 & 62.994 \\
\hline 62.989 & 62.998 & 63.008 & 63.013 & 63.022 \\
\hline 62.967 & 62.990 & 63.017 & 62.964 & 62.995 \\
\hline \multicolumn{5}{|c|}{ Sample No. } \\
\hline 11. & 12. & 13. & 14. & 15. \\
\hline 63.026 & 62.969 & 63.043 & 62.984 & 63.006 \\
\hline 63.026 & 63.013 & 63.046 & 62.958 & 62.993 \\
\hline 62.977 & 62.993 & 62.987 & 63.010 & 63.002 \\
\hline 62.984 & 63.010 & 63.027 & 63.028 & 62.958 \\
\hline 62.999 & 62.998 & 62.986 & 62.961 & 63.014 \\
\hline \multicolumn{5}{|c|}{ Sample No. } \\
\hline 16. & 17. & 18. & 19. & 20. \\
\hline 62.990 & 62.986 & 62.993 & 63.044 & 62.985 \\
\hline 62.987 & 62.993 & 63.002 & 62.926 & 62.989 \\
\hline 62.988 & 62.994 & 62.989 & 63.033 & 63.021 \\
\hline 63.009 & 63.010 & 63.031 & 63.003 & 63.008 \\
\hline 63.003 & 63.001 & 62.979 & 63.009 & 63.014 \\
\hline \multicolumn{5}{|c|}{ Sample No. } \\
\hline 21. & 22. & 23. & 24. & 25. \\
\hline 63.013 & 63.009 & 62.973 & 62.973 & 63.044 \\
\hline 62.978 & 63.028 & 62.987 & 62.987 & 63.008 \\
\hline 63.018 & 62.998 & 62.939 & 62.939 & 62.992 \\
\hline 63.017 & 63.001 & 63.003 & 63.003 & 62.999 \\
\hline 62.974 & 62.980 & 62.998 & 62.998 & 62.989 \\
\hline
\end{tabular}

stable and in control. Parallel to these actions, five rings were randomly selected from the process each day and their inner diameter was measured. Results are presented in Tab. 2 .

Taking into account the fact that this analysis deals with continuous data, the $X$ bar $-R$ control chart was used to ascertain the stability of the process. The capability of attribute data was calculated by using the binomial 
distribution, while the capability of continuous data was calculated by using the normal distribution via the Minitab trial version. The Binomial Process Capability Report is presented in Fig. 1.

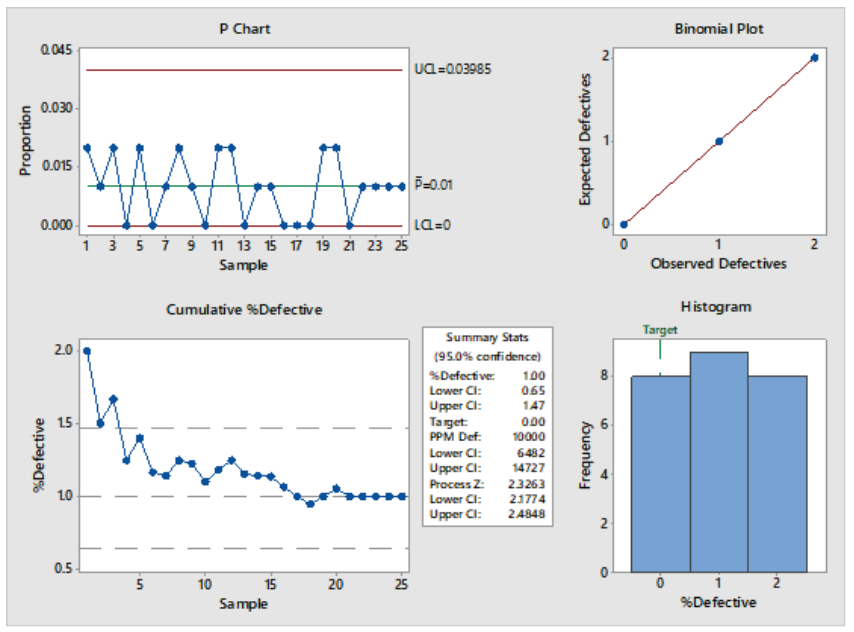

Figure 1 Binomial Process Capability Report

The $p$ chart indicates that there are no data points exceeding the control limits. The chart of the cumulative estimate of the mean percentage of defective items (\% defect) demonstrates that the estimate of the overall defective rate appears to be stabilizing around $1 \%$, but additional data may need to be collected in order to verify this. The process $Z$ equals 2.33 . The process $Z$ (the sigma capability of a process) is the capability index. The larger the process $Z$ is, the better the process is performing. Process $Z$ is computed from the average probability $P$ by determining the value from a standard normal $(0,1)$ distribution so that the area to the right of the value is the average $P$ [8-9].

The results of the process control using the $X$ bar $-R$ control chart are shown in Figs. 2a) and 2b), while the process capability report (normal) is shown in Fig. 3.

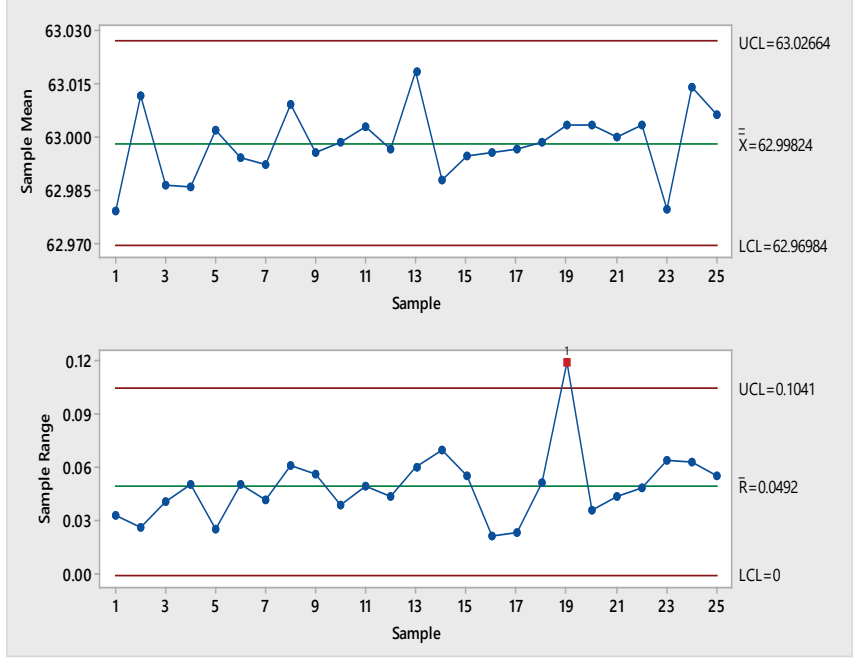

Figure 2 a) $X$ bar $-R$ control charts - Process not under control

In Fig. 2a), the displayed process is not stable, hence it makes no sense to calculate its capability. In such a case, the cause of process instability needs to be investigated and removed. Fig. 2b), on the other hand, displays a process which is stable and under control.

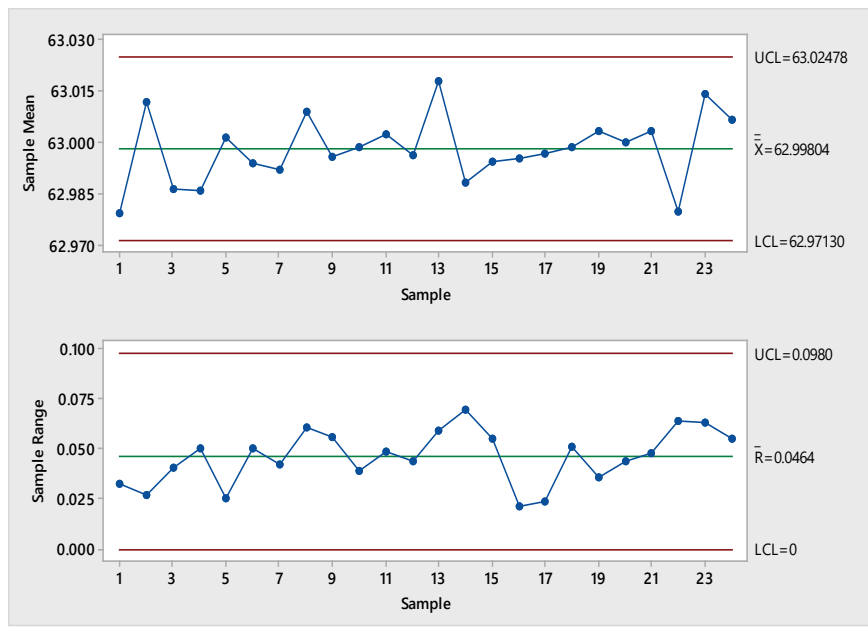

Figure 2 b) $X$ bar $-R$ control charts - Process under control

In accordance with the process capability report (Fig. 3), capability assessments were conducted by calculating the potential capability (process capability) and overall capability (process performance). As shown in Fig. 3, the data follow a normal distribution.

Instead of potential capability indices $C p$ and process performance indices $P p$, the sigma level $Z$.Bench (potential) and sigma level $Z$.Bench (overall) were calculated.

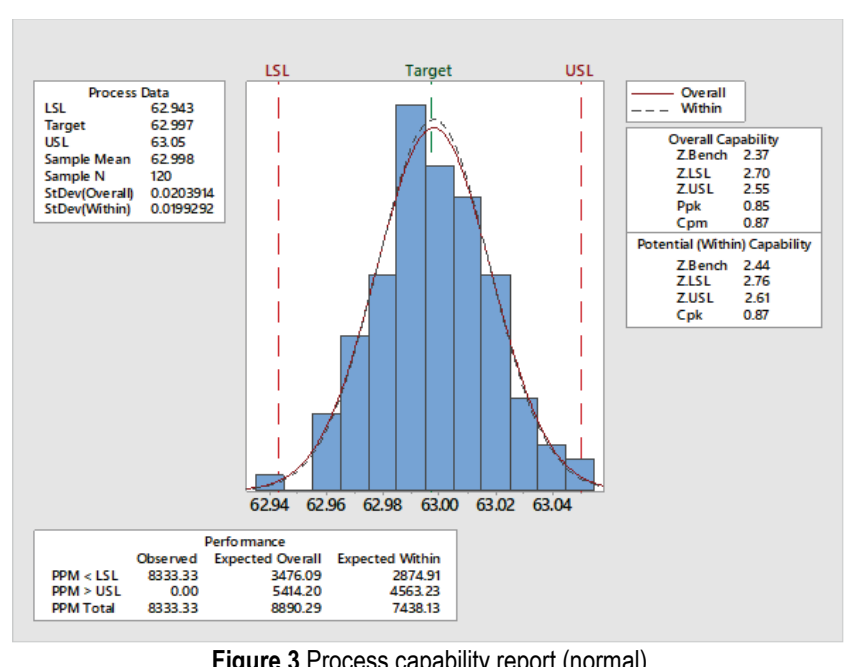

$Z$. Bench is defined by the Eq. (1).

$Z$. Bench $=\phi^{-1}\left(1-P_{1}-P_{2}\right)$

Where:

$P_{1}=\operatorname{Prob}(X<\mathrm{LSL})=1-\phi(Z . \mathrm{LSL})$

$P_{2}=\operatorname{Prob}(X>\mathrm{LSL})=1-\phi(Z . \mathrm{USL})$

$\phi$ - cumulative distribution function of a standard normal distribution

$\phi^{-1}$ - inverse of a cumulative distribution function of a standard normal distribution 
Z.LSL - measure of sigma capability in relation to the upper specification limit

Z.USL - measure of sigma capability in relation to the lower specification limit

Sigma capability in relation to the lower specification limit Z.LSL and sigma capability in relation to the upper specification limit Z.USL are defined by Eqs. (4) and (5).

$Z . \mathrm{LSL}=\frac{\bar{x}-L S L}{\sigma}$,

$Z . \mathrm{USL}=\frac{U S L-\bar{x}}{\sigma}$

Where: $\bar{x}$ - arithmetic mean, $\sigma$ - standard deviation.

The Process capability report (Fig. 3) shows that the process mean $(62.998 \mathrm{~mm})$ is slightly larger than the target $(62.996 \mathrm{~mm})$ and both tails of the distribution fall outside the specification limits. This means that there are rings whose diameter is below the lower specification of $63.943 \mathrm{~mm}$ or greater than the upper specification of $63.050 \mathrm{~mm}$. The Ppk index equals 0.85 , indicating that the process has to be improved by reducing variability and by centering the process on the target. In the case of this production process, its large variation represents the main challenge in assuring process quality, while the process being slightly off target is a secondary issue [10-11]. The benchmark $Z$ statistics is computed by determining the $Z$ value using the standard normal (0.1) distribution [8-9]. The $Z$ benchmark describes the sigma capability of a process. $Z$ LSL and $Z$ USL measure how the process is performing against the specification limits [8-9]. $Z$ Bench equals 2.37 .

The $Z$ score resulting from the analysis of the attribute data amounts to 2.33 and it is very close to the value of the $Z$ Bench obtained from the analysis of the continuous data which is equal to 2.37. It can therefore be concluded that both analyses reached similar conclusions in regard to the sigma level of the process.

\section{CONCLUSION}

The procedure for estimating process capability depends on the data types used. In the first step, it is necessary to check whether the data type is continuous or attributive. In the second step, stability has to be checked by using control charts for continuous or attribute data. Depending on the type of data, the normal capability or binomial capability procedure should be applied. The process capability and process performance can be conducted via the calculation of process capability indices, as well as process performance indices and the sigma level. The sigma level or process sigma represents a good measuring tool that can be used to quantify the ability of process performance of the continuous or attribute data. The process sigma or sigma level is a universal benchmark that can be used to measure the quality of different processes.

\section{REFERENCES}

[1] https://support.minitab.com/en-us/minitab/18/help-and-howto/quality-and-process-improvement/capabilityanalysis/supporting-topics/data-and-data-assumptions/datatypes-for-capability-analysis/

[2] Deming, W. E. (1982). Quality, Productivity and Competitive Position, MIT Press, Cambridge.

[3] Quentin, B. (2010). Lean Six Sigma \& Minitab: The Complete Toolbox Guide for All Lean Six Sigma Practitioners, OPEX Resources, Winchester.

[4] Antony, J., Antony, F. J., Kumar, M., \& Cho, B. R. (2007). Six Sigma in Service Organizations: Benefits, Challenges and Difficulties, Common Myths, Empirical Observation and Success Factors. International Journal of Quality \& Reliability Management, 24(3), 294-311. https://doi.org/10.1108/02656710710730889.

[5] Kotz, S. \& Johnson, N. L. (1993). Process Capability Indices, Chapman \& Hall, London. https://doi.org/10.1007/978-1-4899-4465-8

[6] Harris, T. J. \& Ross, W. H. (1991). Statistical Process Control Procedures for Correlated Observations, Canadian Journal of Chemical Engineering, 69(1), 48-57. https://doi.org/10.1002/cjce.5450690106

[7] Runje, B., Medić, S., Kondić, Ž., Alar, Ž., \& Tunjić, Đ. (2012). Statistical process control of fire-resistant coating production based on thickness measurements. Tehnicki Vjesnik-Technical Gazette. 19(3), 589-593.

[8] https://analyse-it.com/docs/user-guide/process-capability/zbenchmark

[9] https://support.minitab.com/en-us/minitab/18/help-and-howto/quality-and-process-improvement/capabilityanalysis/supporting-topics/capability-metrics/process-zvalues-for-attribute-capability/

[10] Sommerville, S. \& Montgomery, D. C. (1996). Process Capability Indices and Non-Normal Distribution. Quality Engineering, 9(2), 305-316. https://doi.org/10.1080/08982119608919047

[11] Relyea, D. B. (2011). The Practical Application of the Process Capability Study: Evolving from Product Control to Process Control, CRC Press, Boca Raton.

\section{Authors' contacts:}

\author{
Biserka RUNJE, Ph.D. Prof \\ University of Zagreb, \\ Faculty of Mechanical Engineering and Naval Architecture, \\ Ivana Lučića 5, 10000 Zagreb, Croatia \\ biserka.runje@fsb.hr \\ Živko KONDIĆ, Ph.D. Prof. \\ University North, \\ 104 brigade 3,42000 Varaždin, Croatia \\ zivko.kondic@unin.hr \\ Amalija HORVATIĆ NOVAK, Ph.D. \\ University of Zagreb, \\ Faculty of Mechanical Engineering and Naval Architecture, \\ Ivana Lučića 5, 10000 Zagreb, Croatia \\ amalija.horvatic@fsb.hr \\ Zdenka KERAN, Ph.D. Assis. Prof. \\ University of Zagreb, \\ Faculty of Mechanical Engineering and Naval Architecture, \\ Ivana Lučića 5, 10000 Zagreb, Croatia
}

